\title{
EDITORIAL
}

\section{Antibiotics in acute exacerbations of COPD: the good, the bad and the ugly}

\author{
Wim G. Boersma
}

Y ou may well wonder what the connection might be between the title of this editorial and the famous Western The Good, the Bad and the Ugly. Well, we know that antibiotics are effective in treating bacterial infections (the good), are not as harmless as both clinicians and patients may think (the bad), and may have adverse effects and do not work in viral infections (the ugly). There is an increasing awareness that we have to challenge the problems caused by the overuse of antibiotics. Beliefs, expectations and incentives are the drivers of antibiotic overuse among the concerned parties: patients, physicians and society. Therefore, social norms would have to be altered, resulting in a fundamental change in patients' expectations, marketing, indications for antibiotic use and, particularly, physicians' prescription behaviour. In a recent paper by the McDonnell Norms Group [1], some radical solutions were suggested, ranging from "changes in the way physicians are paid for prescribing antibiotics" and "looking at accuracy and limitation of antibiotic use" to "patients might be reimbursed differently for antibiotic prescriptions".

Antibiotic resistance is inevitably related to excessive antibiotic use. The frequency of antibiotic resistance in bacteria among different countries is proportional to their relative rate of antibiotic use [2]. This is generally expressed in defined daily doses per 1,000 inhabitants per day (DID). Countries in southern and eastern Europe have the highest DID, whereas consumption is much lower in northern Europe [1, 3]. Antibiotic consumption differs among various countries in Europe. In 2008, the proportion of outpatient penicillin use ranged from $30.1 \%$ in Germany to $62.6 \%$ in Denmark, whereas the proportional use of quinolones ranged from $3.1 \%$ in the UK to $17.0 \%$ in Russian. Efforts to control overprescribing of antibiotic use can be successful, as has been shown in studies from Finland and Iceland. Reduction in resistance (up to 30\%) can be achieved by implementing specific recommendations that discourage antibiotic treatment $[4,5]$.

Antibiotics are often prescribed, as well as to chronic obstructive pulmonary disease (COPD) patients, for illnesses such as colds, acute bronchitis and related respiratory tract infections caused by viruses that will not respond to antibiotic drugs. The rate of antibiotic prescriptions in the USA, measured from 1995 to 2002, has reduced in those respiratory infections in which antibiotics are rarely indicated [6]. However, the proportion of prescribed antibiotics classified as broad-spectrum antibiotics for these

CORRESPONDENCE: W.G. Boersma, Dept of Pulmonary Diseases, Medical Centre Alkmaar, P0 Box 510,1800AM Alkmaar, The Netherlands. E-mail: w.boersma@mca.nl visits increased from $41 \%$ to $77 \%$. In 2002, data from 360 hospitals reported that 69,820 US adults were hospitalised for an acute exacerbation of COPD (AECOPD) [7]. 87\% of these patients were treated with antibiotics, resulting in broadspectrum coverage in $74 \%$ of cases. However, sputum cultures were performed in only $14.4 \%$ of the patients. One may wonder whether omitting verification of a bacterial infection is justified, and whether it is acceptable to choose the use of broad-spectrum antibiotics for these patients.

Although as many as two-thirds of all cases of AECOPD may be due to viral infections, COPD treatment guidelines nevertheless recommend antibiotic treatment for patients with purulent sputum and either an increase in sputum production or an increase in dyspnoea [8, 9]. The evidence supporting these recommendations comes from a meta-analysis studying 11 trials performed between 1965 and 1992 demonstrating that antibiotics can reduce short-term mortality and treatment failure [10]. Nine trials were performed with hospitalised patients, one of which took place in the intensive care unit and two were carried out in the community. The largest and most leading study is that of ANTHONISEN et al. [11]. In this study three types of exacerbations were introduced, namely: type 1, defined by the triad of increased dyspnoea, sputum volume and sputum purulence; type 2, defined by the presence of two of these symptoms; and type 3, characterised by one of the three symptoms with evidence of fever or an upper respiratory tract infection. A significant benefit from antibiotics was largely reported for (out)patients with type 1 exacerbations, whereas there was no significant difference between antibiotic and placebo in patients with type 3 exacerbations. That type 1 , and to a lesser extent type 2 , exacerbations should be treated with antibiotics has been adopted by several guidelines [9, 12, 13]. Recently, DANIELS et al. [14] reported a placebo-controlled trial in which antibiotic treatment in hospitalised patients (type 1 and type 2 exacerbations) had the same clinical success at day 30 , but showed a higher rate of clinical cure on day 10 than placebo treatment.

When using the criteria of ANTHONISEN et al. [11], the question remains as to whether the reported purulence of sputum is the key message in prescribing antibiotics. Not all patients routinely inspect their expectorated sputum and the patient's response to the doctor's question could be a "best guess". Moreover, sputum may change rapidly, especially during exacerbations. Sputum purulence assessed by a colour chart in the laboratory is related to an increased inflammation and higher bacterial load [15-17]. However, sputum colour is less reliably related to bacterial load if it is reported by patients [17]. 
Are there any other justifications for antibiotic treatment in AECOPD? We know that systemic inflammation is increased in AECOPD and more pronounced in the presence of bacteria $[18,19]$. Biomarkers such as C-reactive protein and procalcitonin, especially when increased levels are detected, are indicative for bacterial infection and may guide antibiotic treatment [20-22]. However, interventional studies should be conducted, looking at the optimal strategy for determining the antibiotic cut-off point.

If antibiotic treatment is indicated, recent European guidelines (European Respiratory Society/European Society for Clinical Microbiology and Infectious Diseases) differentiate between outpatient treatment and hospitalised patients [13]. In the community setting, amoxicillin or tetracycline are preferred, whereas in hospitalised patients, amoxicillin or amoxicillin/clavulanic acid are recommended. Ciprofloxacin and moxifloxacin or levofloxacin are only indicated in patients with risk factors for Pseudomonas aeruginosa and clinically relevant bacterial resistance rates against all first-choice agents, respectively.

In the current issue of the European Respiratory Journal, WILSON et al. [23] report the results of the MAESTRAL study. In this study, the primary end-point was met, showing non-inferiority of moxifloxacin to amoxicillin/clavulanic acid. Only in patients with a positive sputum culture at baseline was moxifloxacin superior to that in patients treated with amoxicillin/clavulanic acid. Is this good news? In my opinion it is not, because a number of objections can be made. First, only one-third of the included patients were treated with a supplemental course of corticosteroids. In the study design it was decided, for medical ethical reasons, that the option to use steroids must be made available to physicians. A recent meta-analysis of 11 studies showed that treatment with corticosteroids (in both out- and inpatients) significantly reduces the rate of treatment failure and the need for additional medical treatment, as well as shortening the hospital stay [24]. For an optimal comparison of both antibiotic treatments concomitant medication should be standardised.

Secondly, at presentation clinicians do not know whether AECOPD patients have bacteria-positive sputum samples. Generally, sputum cultures will only be available 48-72 h after a specimen is obtained. Considering the observation that sputum colour reported by patients is not a reliable marker, it is difficult to assess which patients need antibiotics. This study does not answer the question of whether culture-initiated introduction of moxifloxacin is superior to other antibiotic treatments. The potent effect of moxifloxacin was demonstrated in another study indicating that the drug may prolong the time to the next exacerbation [25].

Thirdly, the participation of many countries with different healthcare systems may influence the generalisation of the findings of the MAESTRAL study. For instance, inhaled corticosteroids are used more often in Western Europe than in other countries; in this study, that is $\sim 53 \%$ overall [23]. Since inhaled corticosteroids, either combined with long-acting bronchodilators or not, may reduce the number of AECOPD, outcome may be affected by differences in prescription. Another point of concern regarding this type of study is the risk of selection bias, which is introduced when small numbers are entered by many countries.
What direction do we take with AECOPD? In my opinion, AECOPD should not be treated with antibiotics as standard. A pitfall is the sputum colour reported by the patient. Clinicians, especially in the outpatient setting, may not actually see sputum specimens and, thus, may respond to the patient's report and prescribe antibiotics if sputum is discoloured. How can we change this attitude? Assessment of sputum colour using a nine-point colour chart may be an option [16, 26]. If outpatient sputum is cream, white or clear, the yield from bacteriological analysis is low. Another way to reduce antibiotic use is to delay its prescription in patients who are not severely ill. Wait and see how effective treatment with corticosteroids and bronchodilators is and, in those patients who fail to improve, add an antibiotic after 4 days. And, if an antibiotic is prescribed, do this for just a short period [27]. As mentioned earlier, we have to change our social norms towards antibiotic use. Solutions to reduce the number of exacerbations, such as azithromycin maintenance therapy and moxifloxacin pulse therapy, may be attractive in the short term, but eventually we have to face the threat of resistance and economic impact [28, 29].

Further studies should be undertaken investigating biomarkers to guide antibiotic treatment and investigate the optimal duration of antibiotic treatment.

\section{STATEMENT OF INTEREST}

A statement of interest for W.G. Boersma can be found at www.erj. ersjournals.com/site/misc/statements.xhtml

\section{REFERENCES}

1 McDonnell Norms Group. Antibiotic overuse: the influence of social norms. J Am Coll Surg 2008; 207: 265-275.

2 Goossens H, Ferech M, Vander SR, et al. Outpatient antibiotic use in Europe and association with resistance: a cross-national database study. Lancet 2005; 365: 579-587.

3 Vander Stichele RH, Elseviers MM, Ferech M, et al. Hospital consumption of antibiotics in 15 European countries: results of the ESAC Retrospective Data Collection (1997-2002). J Antimicrob Chemother 2006; 58: 159-167.

4 Seppala H, Klaukka T, Vuopio-Varkila J, et al. The effect of changes in the consumption of macrolide antibiotics on erythromycin resistance in group A streptococci in Finland. Finnish Study Group for Antimicrobial Resistance. N Engl J Med 1997; 337: 441-446.

5 Kristinsson KG. [Epidemiology of penicillin resistant pneumococci]. Laeknabladid 1996; 82: 9-19.

6 Roumie CL, Halasa NB, Grijalva CG, et al. Trends in antibiotic prescribing for adults in the United States - 1995 to 2002. J Gen Intern Med 2005; 20: 697-702.

7 Lindenauer PK, Pekow P, Gao S, et al. Quality of care for patients hospitalized for acute exacerbations of chronic obstructive pulmonary disease. Ann Intern Med 2006; 144: 894-903.

8 Snow V, Lascher S, Mottur-Pilson C. The evidence base for management of acute exacerbations of COPD: clinical practice guideline, part 1. Chest 2001; 119: 1185-1189.

9 Rabe KF, Hurd S, Anzueto A, et al. Global strategy for the diagnosis, management, and prevention of chronic obstructive pulmonary disease: GOLD executive summary. Am J Respir Crit Care Med 2007; 176: 532-555.

10 Ram FS, Rodriguez-Roisin R, Granados-Navarrete A, et al. Antibiotics for exacerbations of chronic obstructive pulmonary disease. Cochrane Database Syst Rev 2006; 2: CD004403. 
11 Anthonisen NR, Manfreda J, Warren CP, et al. Antibiotic therapy in exacerbations of chronic obstructive pulmonary disease. Ann Intern Med 1987; 106: 196-204.

12 Woodhead M, Blasi F, Ewig S, et al. Guidelines for the management of adult lower respiratory tract infections. Eur Respir J 2005; 26: $1138-1180$.

13 Woodhead M, Blasi F, Ewig S, et al. Guidelines for the management of adult lower respiratory tract infections - full version. Clin Microbiol Infect 2011; 17: Suppl. 6, E1-E59.

14 Daniels JM, Snijders D, de Graaff CS, et al. Antibiotics in addition to systemic corticosteroids for acute exacerbations of chronic obstructive pulmonary disease. Am J Respir Crit Care Med 2010; 181: 150-157.

15 Stockley RA, O'Brien C, Pye A, et al. Relationship of sputum color to nature and outpatient management of acute exacerbations of COPD. Chest 2000; 117: 1638-1645.

16 Stockley RA, Bayley D, Hill SL, et al. Assessment of airway neutrophils by sputum colour: correlation with airways inflammation. Thorax 2001; 56: 366-372.

17 Daniels JM, de Graaff CS, Vlaspolder F, et al. Sputum colour reported by patients is not a reliable marker of the presence of bacteria in acute exacerbations of chronic obstructive pulmonary disease. Clin Microbiol Infect 2010; 16: 583-588.

18 Perera WR, Hurst JR, Wilkinson TM, et al. Inflammatory changes, recovery and recurrence at COPD exacerbation. Eur Respir J 2007; 29: 527-534.

19 Stockley RA, O'Brien C, Pye A, et al. Relationship of sputum color to nature and outpatient management of acute exacerbations of COPD. Chest 2000; 117: 1638-1645.
20 Hurst JR, Donaldson GC, Perera WR, et al. Use of plasma biomarkers at exacerbation of chronic obstructive pulmonary disease. Am J Respir Crit Care Med 2006; 174: 867-874.

21 Stolz D, Christ-Crain M, Bingisser R, et al. Antibiotic treatment of exacerbations of COPD: a randomized, controlled trial comparing procalcitonin-guidance with standard therapy. Chest 2007; 131: 9-19.

22 Daniels JM, Schoorl M, Snijders D, et al. Procalcitonin vs C-reactive protein as predictive markers of response to antibiotic therapy in acute exacerbations of COPD. Chest 2010; 138: 1108-1115.

23 Wilson R, Anzueto A, Miravitlles M, et al. Moxifloxacin versus amoxicillin/clavulanic acid in outpatient acute exacerbations of COPD: MAESTRAL results. Eur Respir J 2012; 40: 17-27.

24 Walters JA, Gibson PG, Wood-Baker R, et al. Systemic corticosteroids for acute exacerbations of chronic obstructive pulmonary disease. Cochrane Database Syst Rev 2009; 1: CD001288.

25 Wilson R, Allegra L, Huchon G, et al. Short-term and long-term outcomes of moxifloxacin compared to standard antibiotic treatment in acute exacerbations of chronic bronchitis. Chest 2004; 125: 953-964.

26 Johnson AL, Hampson DF, Hampson NB. Sputum color: potential implications for clinical practice. Respir Care 2008; 53: 450-454.

27 El Moussaoui R, Roede BM, Speelman P, et al. Short-course antibiotic treatment in acute exacerbations of chronic bronchitis and COPD: a meta-analysis of double-blind studies. Thorax 2008; 63: 415-422.

28 Albert RK, Connett J, Bailey WC, et al. Azithromycin for prevention of exacerbations of COPD. N Engl J Med 2011; 365: 689-698.

29 Sethi S, Jones PW, Theron MS, et al. Pulsed moxifloxacin for the prevention of exacerbations of chronic obstructive pulmonary disease: a randomized controlled trial. Respir Res 2010; 11: 10. 